\title{
Micro gas sensor by MEMS processes for selective dual gas detection of carbon monoxide and methane
}

\author{
$\underline{\text { Inho Kim }}^{1,2}$, Kyungdeog Nam ${ }^{1}$, Won-Youl Choi ${ }^{3,4^{*}}$, Young-Won Song ${ }^{5^{*}}$ \\ ${ }^{1}$ Department of Chemical Engineering, Ajou University, Suwon Gyeonggi-do 443-749, South Korea \\ ${ }^{2}$ R\&D Center, Maccon Inc., Bucheon Gyeonggi-do 421-170, South Korea \\ ${ }^{3}$ Department of Advanced Materials Engineering, Gangneung-Wonju National University, Gangneung \\ Gangwon 210-702, South Korea \\ ${ }^{4}$ Research Institute for Dental Engineering, Gangneung- Wonju National University, Gangneung \\ Gangwon 210-702, South Korea \\ ${ }^{5}$ Interface Control Research Center, Korea Institute of Science and Technology, Seongbuk-gu Seoul \\ 136-791, South Korea \\ cwy@gwnu.ac.kr (W.-Y. Choi), ysong@kist.re.kr (Y.-W. Song)
}

\begin{abstract}
We have designed and fabricated micro platform for gas sensor including micro heater and electrode using micro electro-mechanical system (MEMS) processes, and $\mathrm{SnO}_{2}$ nanopowder have been mounted on the platform. The fabricated micro platform was $2.5 \mathrm{~mm} \times 2.5 \mathrm{~mm}$ in size and power consumptions were $9 \mathrm{~mW}$ and $110 \mathrm{~mW}$ for $\mathrm{CO}$ and $\mathrm{CH}_{4}$ operation temperatures, respectively. The gas sensing performances for 200 ppm CO and 12,500 ppm $\mathrm{CH}_{4}$ were investigated at $50{ }^{\circ} \mathrm{C}$ and $330^{\circ} \mathrm{C}$.
\end{abstract}

Key words: $\mathrm{MEMS}$, gas sensor, $\mathrm{CO}, \mathrm{CH}_{4}$, periodic temperature modulation

\section{Introduction}

Many researches have conducted to develop the gas sensors using semiconductor metal oxide, and most of applications were limited within safety systems in domestic and industrial areas. However recently, the gas sensors must have a high sensitivity and accuracy, and fast response because of increasing application fields, such as ventilation controls, cooking controls, combustion controls, automobile, and odor detection, etc. [1]. Normally, practical and effective gas detection with semiconductor metal oxide requires an optimized operating temperature [2]. Moreover, low power consumption offers the possibility of wide application. Especially selective detection of carbon monoxide and methane is required for many applications in the field of fuel combustion. Thus, several ways within the electronic interface circuit can be employed for controlling the heater [3].

In our work, a micro platform for gas sensor was designed and fabricated using microelectro-mechanical systems (MEMS) processes. The semiconductor metal oxide, $\mathrm{SnO}_{2}$ was used as a gas sensing material. The gas sensing performances of $\mathrm{CO}$ and $\mathrm{CH}_{4}$ of their
STEL (short time exposure limit) and \%LEL (lower explosion limit) were investigated.

\section{Experiments}

The micro platform for gas sensor including micro heater and interdigitated electrode on the membrane was designed as shown in Fig. 1. A p-type Si (100) wafer with $500 \mu \mathrm{m}$ thickness and 4 inch diameter was deposited by $2 \mu \mathrm{m}$ thickness $\mathrm{SiN}_{\mathrm{x}}$ film on both sides using LPCVD (low pressure chemical vapor deposition). A platinum film with thickness of $200 \mathrm{~nm}$ was deposited on the front side of the wafer and micro heater was formed by photolithography. The insulation layer, $\mathrm{SiO}_{2}-\mathrm{SiN}_{\mathrm{x}}-\mathrm{SiO}_{2}$ by $\mathrm{PECVD}$ (plasma enhanced chemical vapor deposition) deposited on the micro heater. Then the interdigitated electrodes which were $150 \mathrm{~nm}$ thickness of platinum were formed by photolithography. Finally, the membrane formed on the back side of the wafer by anisotropic etching of the bulk silicon using $\mathrm{KOH}$ solution.

The sensing material, $\mathrm{SnO}_{2}$ nanopowder (Tin(IV) oxide, APS 80nm, American Elements) was applied on the interdigitated electrode of the micro platform by screen printing and heat treatment at $400{ }^{\circ} \mathrm{C}$ for $1 \mathrm{~h}$. Fig. 2 shows the simple circuit which was operated a gas sensor in the chamber, measured the voltage across 
load resistance $\left(V_{\text {out }}\right)$ as a sensing signals. The gas sensing properties of the dual gases, $\mathrm{CO}$ and $\mathrm{CH}_{4}$ were investigated as a function of their concentration.

\section{Results and discussion}

Fig. 3 shows the power consumption with heater voltage $\left(V_{H}\right)$ of MEMS micro platform. The average power consumptions of MEMS micro platform were typically increased. The measured power consumptions were $9 \mathrm{~mW}$ and $110 \mathrm{~mW}$ at low and high heater voltages which were corresponded to modulation temperatures, $52.8^{\circ} \mathrm{C}$ and $331^{\circ} \mathrm{C}$, respectively.

The gas sensing properties of the $\mathrm{CO}$ and $\mathrm{CH}_{4}$ gases were tested with sensor operation circuit shown in Fig. 4. The output voltage $\left(V_{\text {out }}\right)$ means a voltage across load resistance and the

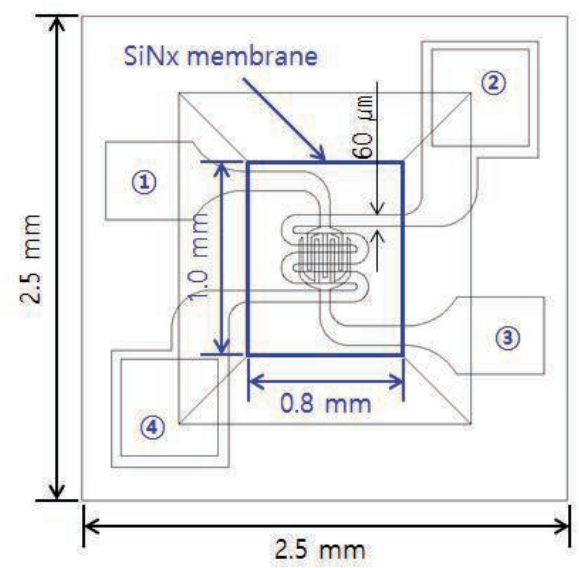

Fig. 1. The design of micro platform for gas sensor (1), (3): interdigitated electrode pads, (2), (4): micro heater pads)

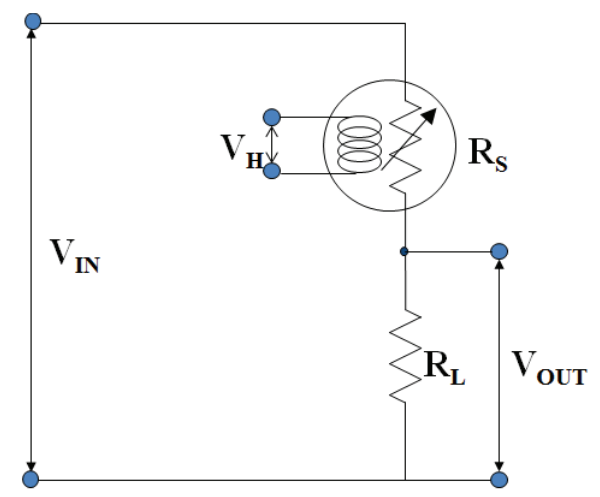

$\mathrm{V}_{\mathrm{IN}}$ : Circuit Voltage

$\mathrm{R}_{\mathrm{S}}$ : Sensor Resistance

$\mathrm{R}_{\mathrm{L}}$ : Load Resistance

$\mathrm{V}_{\text {OUT }}$ : Voltage across load resistance

Fig. 2. The simple circuit diagram for gas sensor operation,

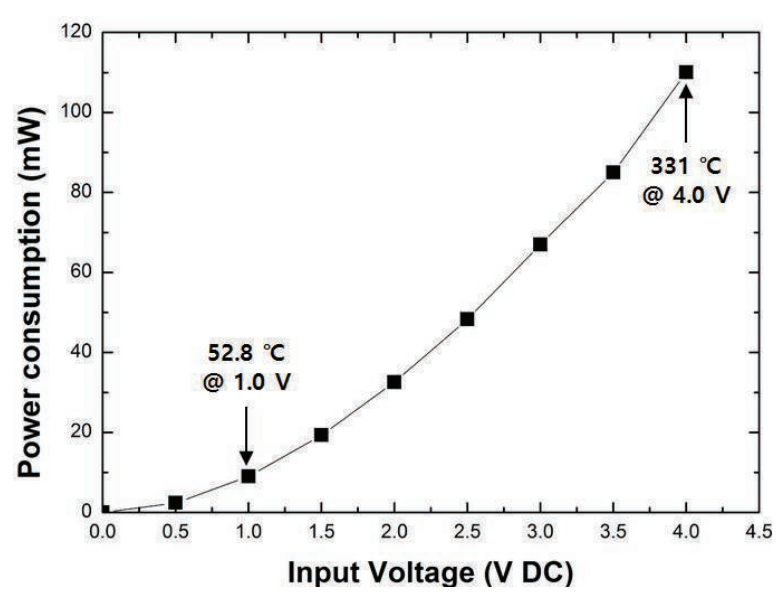

Fig. 3. Measurement of power consumptions with heater voltages $\left(V_{H}\right)$ of the micro platform

$V_{\text {out }}$ value was adjusted $0.1 \mathrm{~V}$ in air using variable resistor. Different operation temperatures between $\mathrm{CO}$ and $\mathrm{CH}_{4}$ tests were realized through change of applied micro heater voltages $\left(V_{H}\right), 1 \mathrm{~V}$ for $\mathrm{CO}$ and $4 \mathrm{~V}$ for $\mathrm{CH}_{4}$. The gases concentrations for the test were $200 \mathrm{ppm}$ of $\mathrm{CO}$ and $12,500 \mathrm{ppm}$ of $\mathrm{CH}_{4}$ because of correspond to STEL (short time exposure limit) and $25 \%$ \%EL (lower explosion limit), respectively. The difference of $V_{\text {out }}\left(\Delta V_{\text {out }}=\Delta V_{\text {out }}\right.$, gas $-\Delta V_{\text {out, air }}$ ) were $349 \mathrm{mV}$ for 200 ppm CO and 1,301 mV for 12,500 ppm $\mathrm{CH}_{4}$.

Furthermore, compared to Fig. 4 (a) and (b), the response of $\mathrm{CH}_{4}$ can be seen further sharpness, therefore the response time of $\mathrm{CH}_{4}$ was faster than that of $\mathrm{CO}$. On the basis of these results, dual gases detection is possible with single gas sensor through the periodic operation temperature modulation.

\section{Conclusion}

The micro gas sensors, $2.5 \mathrm{~mm} \times 2.5 \mathrm{~mm}$ in size were fabricated by MEMS processes. Their detection characteristics to $\mathrm{CO}$ and $\mathrm{CH}_{4}$ were measured at different operation conditions. The power consumptions of micro platform were 9 $\mathrm{mW}$ and $110 \mathrm{~mW}$ for $1 \mathrm{~V}$ and $4 \mathrm{~V}$ of $V_{H}$, and their temperatures of micro heater surface were $52.8^{\circ} \mathrm{C}$ and $331^{\circ} \mathrm{C}$, respectively. Gas detection performances of single sensor device were investigated for dual gases, $200 \mathrm{ppm} \mathrm{CO}$ and $12,500 \mathrm{ppm} \mathrm{CH}_{4}$. The output signals in the operation circuit were $349 \mathrm{mV}$ and 1,200 mV for $\mathrm{CO}$ and $\mathrm{CH}_{4}$, respectively. Dual gases detection is possible with single gas sensor device through the change of their operating conditions. 

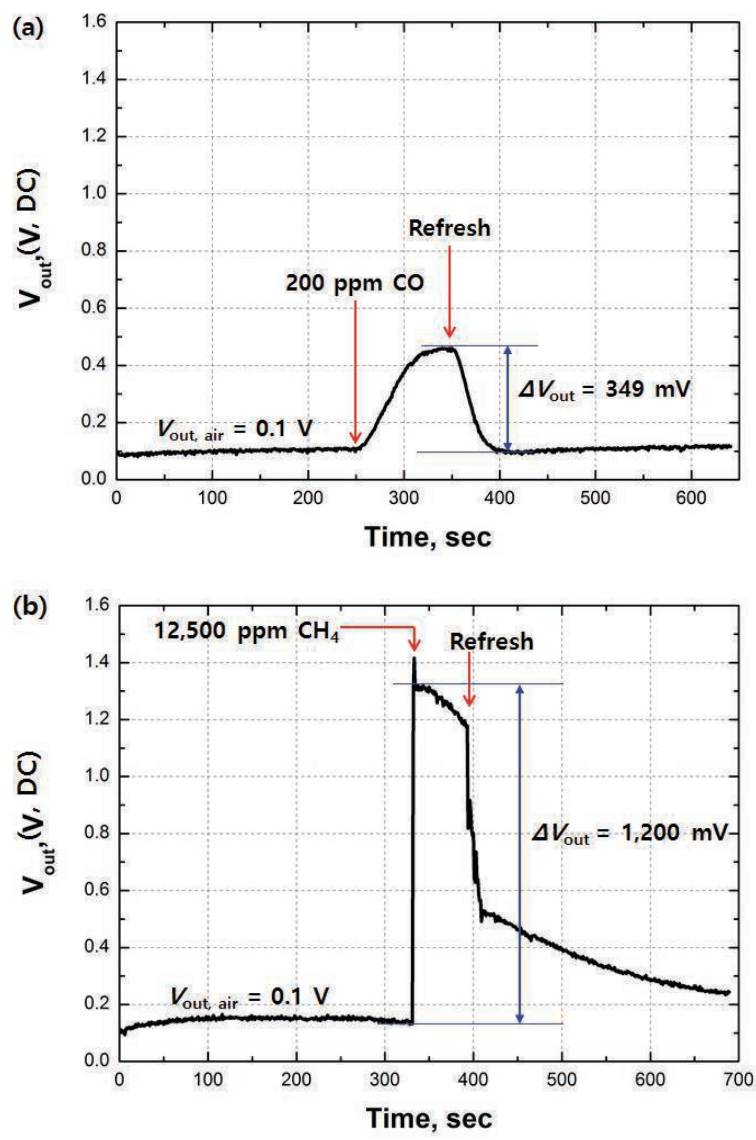

Fig. 4. Gas sensing properties for (a) 200 ppm $\mathrm{CO}$ and (b) 12,500 ppm $\mathrm{CH}_{4}$

\section{References}

[1] A. Kolmakov, M. Moskovits, The Chemical sensing and catalysis by one-dimensional metaloxide nanostructurs, Annual Review of Materials Research 34, 151-180 (2004); doi:

10.1146/annurev.matsci.34.040203.112141

[2] S. R. Morrison, Selectivity in semiconductor gas sensors, Sensors and Actuators B Chemical, 12, 425-440 (1987); doi: 10.1016/02506874(87)80061-1

[3] M. Baroncini, P. Placidi, G.C. Cardinali, A. Scorzoni, A simple interface circuit for micromachined gas sensors, Sensors and Actuators A: Physical 109, 131-136 (2003); doi: 10.1016/S0924-4247(03)00348-0 